\title{
Observational study of compliance with infection control practices among healthcare workers in subsidized and private residential care homes
}

\author{
Jessie Kit Ling $\mathrm{Au}^{1+}$, Lorna Kwai Ping Suen ${ }^{2}$ (D) and Simon Ching $\operatorname{Lam}^{1,3^{*+}}$ (D)
}

\begin{abstract}
Background: The elderly population in Hong Kong is rapidly growing, and the need for residential care homes $(\mathrm{RCHs})$ is increasing. The risk of being infected with micro-organisms increases among the frail and the vulnerable elderly population as their immunity system begins to deteriorate. Furthermore, the residents in $\mathrm{RCH}$ are at high risk of healthcare-associated infections (HAls) due to the confined living environments and individual comorbidities. In relation to this, infection control practice (ICP) is considered a crucial and effective approach in preventing HAls. This study aimed to observe the daily ICP of healthcare workers in RCH settings.

Methods: An observational study was conducted to observe daily ICP among healthcare workers in private and subsidized RCHs. Each RCH was separated into different units based on the location (common area and bedroom area) and nature of residents for successive days. The ICP episodes were observed until 200 opportunities in each unit. The ICP episodes were recorded by an electronic tool called "eRub," which is an ICP checklist based on international guidelines.

Results: The most frequent observed ICP episodes were hand hygiene $(n=1053)$, the use of gloves $(n=1053)$ and respiratory protection $(n=1053)$. The overall compliance of hand hygiene was poor, with only $15 \%$ of participants performing this during the "five moments for hand hygiene." Furthermore, the observations showed that 77.9\% improperly performed the use of gloves, and 31.8\% failed to wear a mask during the care provision for the elderly. However, the results showed that most healthcare workers can wear the mask in a proper way when they should. Generally, the personal care workers were the worst in terms of hand hygiene and use of gloves compared with the other types of healthcare workers.
\end{abstract}

(Continued on next page)

\footnotetext{
*Correspondence: simon.clam@polyu.edu.hk; simlc@alumni.cuhk.net

${ }^{\dagger}$ Jessie Kit Ling Au and Simon Ching Lam contributed equally to this work.

'School of Nursing, The Hong Kong Polytechnic University, Hong Kong, Hong Kong SAR

${ }^{3}$ Squina International Centre for Infection Control, The Hong Kong Polytechnic University, Hong Kong, Hong Kong SAR

Full list of author information is available at the end of the article
}

(c) The Author(s). 2021 Open Access This article is licensed under a Creative Commons Attribution 4.0 International License, which permits use, sharing, adaptation, distribution and reproduction in any medium or format, as long as you give appropriate credit to the original author(s) and the source, provide a link to the Creative Commons licence, and indicate if changes were made. The images or other third party material in this article are included in the article's Creative Commons licence, unless indicated otherwise in a credit line to the material. If material is not included in the article's Creative Commons licence and your intended use is not permitted by statutory regulation or exceeds the permitted use, you will need to obtain permission directly from the copyright holder. To view a copy of this licence, visit http://creativecommons.org/licenses/by/4.0/. The Creative Commons Public Domain Dedication waiver (http://creativecommons.org/publicdomain/zero/1.0/) applies to the data made available in this article, unless otherwise stated in a credit line to the data. 
(Continued from previous page)

Conclusions: Despite the fact that the practice of hand hygiene, the use of gloves, and respiratory protection were the important elements of ICP, overall compliance to these elements was still poor. Personal care workers had the most frequent contact with the residents, but they had the worst compliance rate. Hence, continued monitoring and training among healthcare workers is needed, particularly personal care workers, in this healthcare service setting.

Keywords: Residential care homes, Infection control practice, Healthcare workers, Hand hygiene, Use of gloves, Respiratory protection

\section{Background}

Healthcare-associated infections (HAIs) are the infections incurred by patients during the process of caring in a healthcare setting. In 2019, The World Health Organization reported that about 7 and $10 \%$ of the populations in developed and developing countries, respectively, suffer from HAIs. It is a widespread issue that has threatened the patients' safety within healthcare delivery systems around the world [1-3].

It has been estimated that 1.13-2.68 million infections occurred in nursing homes in the US in 2013 [4]. A study of HAIs in a long-term care facility (HALT) project in a Dutch facility from 2010 to 2017 showed that the average infection prevalence rates were 6.7 and $2.2 \%$ from 2007 to 2011 and from 2012 to 2017, respectively [5]. Another similar study estimated that 2.6 million residents were confirmed to have HAIs each year in Europe [6].

In Hong Kong, the overall prevalence of infection in $\mathrm{RCH}$ sas $2.7 \%$ in 2016, which was lower than that in 2006 (5.7\%) [7]. Methicillin-resistant Staphylococcus aureus (MRSA), a common pathogen causing HAIs, is endemic in Hong Kong. The prevalence of MRSA was estimated at $30.1 \%$ in Hong Kong $\mathrm{RCHs}$, much higher than those reported in previous studies in 2005 (2.8\%) and $2001(21.6 \%)[8,9]$. The MRSA transmission was also reported to be more serious in RCHs than in hospitals [10].

Most of HAIs can be prevented effectively through the optimum infection control practice (ICP) [11]. ICP aims to prevent the risk of disease transmission by contact with blood, bodily fluid, mucous membranes, and nonintact skin. This implies that compliance with ICP is closely related to the risk of HAIs, yet empirical studies have shown that ICP compliance is suboptimal among healthcare practitioners in different countries [1, 12, 13]. However, most of the ICP compliance studies have focused on the hospital setting. To date, studies on ICP compliance among healthcare workers in $\mathrm{RCHs}$ in Hong Kong are limited, and the ICP has yet to be fully documented in this setting.

$\mathrm{RCHs}$ are a kind of long-term care facility that provide different levels of care to the elderly with social and/or physical problems. Long-term care facilities are mainly classified into subsidized and private institutions. All
RCHs must operate in accordance with the code of practice licensed by the Residential Care Homes Ordinance [14]. The code of practice includes infection control, which requires $\mathrm{RCH}$ to follow the guidelines developed by the Centre for Health Protection of the Department of Health. Therefore, healthcare workers should adopt ICP while performing patient care in $\mathrm{RCHs}$.

Meanwhile, the population of Hong Kong is rapidly aging. According to the Hong Kong Census and Statistics Department, the population over 65 is estimated to increase from $17 \%$ in 2016 to $37 \%$ in 2066. Meanwhile, epidemiologic studies mentioned that the elderly tend to have worse complications if they sustain infections. The frail and vulnerable elderly populations in $\mathrm{RCHs}$ are easily infected with micro-organisms. Moreover, the residents in $\mathrm{RCHs}$ are at high risk of HAIs because of the confined living environments and individual comorbidities [7]. In the RCHs, the residents are living collectively, which means they share many facilities and common areas with others [15]. Such a living situation within a confined environment poses a risk of cross infection, particularly those transmissions through airborne particles, water droplets, and personal contact. In addition, because of the demand for basic care, many frail residents must always be in close contact with healthcare workers. This increases a risk of HAI transmission between the staff and residents [16]. Finally, most of the residents in $\mathrm{RCHs}$ are suffering from multiple diseases, e.g., Diabetes Mellitus, stroke, heart disease, etc. $[17,18]$, which are likely to cause HAIs among the elderly. These are the leading causes of morbidity and mortality among the elderly and are known to increase burden on the healthcare system. Therefore, compliance with ICP among healthcare workers is important and has drawn researchers' attention in the past 20 years. As such, the current study aimed to observe the ICP compliance of healthcare workers in private and government-subsidized RCHs.

\section{Methods}

\section{Design and methods}

We collected the demographic data during the first onsite visit in each $\mathrm{RCH}$ unit included in this study. The 
demographic data included the following: number of residents, number of healthcare workers, availability of alcohol-based hand rubs (ABHR), and availability of washing facilities. The observations of ICP include hand hygiene, use of gloves, use of personal protective equipment (PPE), respiratory hygiene, handling of sharp equipment, decontamination of equipment, waste management, and environmental cleaning [13, 14, 19].

We conducted an observational study to observe ICP among healthcare workers in private and governmentsubsidized RCHs. In this study, the researcher (as a nonparticipant observer) was a qualified registered nurse who had been trained and had accumulated experience in patient care. This ensured that the researcher was familiar with ICP. The researcher recorded observations at any time in different shifts (morning or afternoon shifts) every day (from Monday to Sunday) in different units of both the private and subsidized RCHs. This allowed for the collection of comprehensive data on staff behavioral changes in different shifts during the weekdays and weekends [19]. For such consecutive observations done for 2-3 weeks in each $\mathrm{RCH}$, the Hawthorne effect was reduced by desensitizing the healthcare workers to the frequent presence of the observer. Such a method has been suggested elsewhere [20] and is considered more reliable for continuous sampling. The observed healthcare workers were chosen randomly to minimize the selection bias. Once the observed staff was chosen, the researcher did not interrupt the care procedure. As the opportunities occurred, the performances were recorded by using an electronic tool, called the "eRub." According to the guideline, hand hygiene involved ABHR and the use of soap and water for at least $20 \mathrm{~s}$ under the condition of the "five moments for hand hygiene" [21].

\section{Setting}

The studied setting included both subsidized and private $\mathrm{RCHs}$ with similar sizes in order to reduce the confounding factors in different RCHs. A list of RCHs was retrieved from the Social Welfare Department to identify the private and subsidized care attention homes for the elderly. Such homes for the elderly are the most common types of $\mathrm{RCHs}$ in Hong Kong, making up 80\% of the total. Thus, this can be considered as a representative sample. Medium-sized RCHs with three floors and around 200 residents were invited by contacting the superintendent/managers by phone.

The subsidized RCHs had $180-220$ beds, $99 \%$ of which were occupied throughout the year. Single rooms were unavailable and four to eight residents of the same gender shared a partitioned room per bed unit. The toilet and bathroom were shared within a room. The RCHs employed over 90 staff members (staff-to-resident ratio is about 1:2-3) to provide diverse care and services. Staff in $\mathrm{RCHs}$ included professional staff (i.e., registered nurses, enrolled nurses, physiotherapist and occupational therapist), health workers, personal care workers, and workmen.

In comparison, in private $\mathrm{RCHs}$, specific levels or categories of care do not exist. These homes accommodate about 150-300 residents who require diverse levels of care, ranging from minimal personal care to medium nursing care. Only about $70-80 \%$ of beds are occupied throughout the year. Some single rooms are provided, but rooms shared by 4-12 residents of the same gender are common. However, toilets and bathrooms are shared with all residents in the same floor. The common areas include the combined sitting and dining room, the recreation room, and the consultation and treatment rooms. In terms of staffing, these homes employ about 50-70 staff members (approximate ratio of staff to residents is 1:4-5) to provide a diverse range of care and services, including basic care, nursing care, social and support services, food preparation, and housekeeping. The core staff includes professional staff (i.e., registered nurses and enrolled nurses), personal care workers and workmen. Social workers, physiotherapists and occupational therapists work on part-time basis or are shared within and among the organizations. Although the duties and work patterns are similar to those of subsidized RCHs, the ratios of different staff grades vary. For example, such homes have scarce nursing staff but more personal care workers. According to the regional authority body and statute [14], annual infection control training for all healthcare workers working in $\mathrm{RCH}$ is mandatory.

For observations, in every $\mathrm{RCH}$, we separated each floor into several units depending on the geographic location (i.e., common area and bedroom area), because of the difference in intensity and types of care provided. A common area (e.g., dining area) is the place shared by all the residents, and most of the group activities are held there. Bedrooms are for resting and receiving direct personal care, such as wound dressing and tube feeding. Finally, there are 6 units in the subsidized RCHs (3 units of common areas, 3 units of residential bedrooms) and 5 units in private RCHs ( 2 units common of areas and 3 units of residential bedrooms). The floor with only bedbound residents (18 residents) in private $\mathrm{RCHs}$ was not accessible for making observations, because the relatives of the residents refused to allow the observations around.

\section{Samples and sampling methods}

According to the World Health Organization (WHO) guideline [21], the minimum sample size for hand hygiene audit is 200 opportunities per unit per observation period, and each observation session should be $20 \mathrm{~min}$ (up to $10 \mathrm{~min}$ longer or shorter) with no more than 
three observed participants to be observed simultaneously. Our researcher strictly followed these guidelines. The observation targets were healthcare workers, including nurses (registered nurses and enrolled nurses), allied healthcare professionals (AHCPs, i.e., physiotherapists and occupational therapists), health workers (HWs) and personal care worker (PCWs), who were the ones directly giving care for the elderly.

\section{Measurement}

We recorded the ICP episodes by using an electronic tool called "eRub," which is the checklist of ICP by international guideline $[14,21]$. The observation items in the eRub include hand hygiene performance, use of gloves, respiratory hygiene, disinfecting used surfaces/equipment, handling of linen, handling of clinical waste, handling of sharp equipment, use of PPEs, and likelihood of hand colonization. This electronic tool is convenient for observers as it allows them to gather data immediately and saves time for data entry. Furthermore, using the mobile phone for data collection is better than the penand-paper method, because it can reduce the errors committed in gathering large amounts of data and can be more unobtrusive in performing observation.

The interrater agreement test between a research nurse (one observer for all data collection) and infection control expert was established by using WHO Training Film in the Implementation Toolkit. The score of $>0.8$ reliability was achieved before the commencement of data collection. This test is important in ensuring the consistency of an observer's observational rating and increasing the validity of the data obtained [22].

A three-point scale was used to calculate the hand hygiene performance score $(0=$ missing to perform, $1=$ performed with hand hygiene $<20 \mathrm{~s}$, and $2=$ well performed with hand hygiene $>20 \mathrm{~s})$, use of gloves $(0=$ did not perform, $1=$ improperly performed, and $2=$ properly performed), and respiratory hygiene $(0=$ did not perform, $1=$ improperly performed, and $2=$ properly performed).

\section{Data analysis}

Descriptive and inferential statistics were used to analyze the data by using SPSS (Window version 25.0). The ICP episodes were summarized by descriptive statistics. The significant differences in performance scores between healthcare workers working in private and subsidized $\mathrm{RCHs}$ and between those in common areas and residential room areas were determined by independent $t$-tests. The different performance scores of the healthcare workers were compared by using One-way ANOVA test and post-hoc analyses. Two variables (hand hygiene performance and use of gloves) were calculated by Pearson product moment correlations.

\section{Results}

The demographic data included the number of residents, the number of healthcare workers, number of sinks for handwashing, and number of ABHRs in private and subsidized RCHs. The data are presented in Table 1. The final sample contained 1053 (46.1\%) and 1231 (53.9\%) observations in private and subsidized $\mathrm{RCHs}$, respectively. Hand hygiene performance, use of gloves, and respiratory protection were the most observed episodes in ICP. Other episodes of ICP, such as disinfecting used surfaces/equipment, handling of linen, handling of clinical waste, handling of sharp equipment, use of PPEs, and the likelihood of hand colonization were uncommon and difficult to record in this setting. The sampled episodes of healthcare workers included PCWs: 1474 (64.5\%), HW: 349 (64.5\%), nurses: 349 (18.4\%), AHCPs: $36(1.6 \%)$, and doctors: $5(0.2 \%)$. The overall change of hand hygiene performance was minimal and steady over the observation period in both types of RCHs (Fig. 1).

The most frequently observed ICP elements were hand hygiene, use of gloves, and respiratory practice. In this setting, other elements of ICP were seldom observed. Thus, our analysis focused on hand hygiene, use of gloves and respiratory hygiene score among healthcare workers in subsidized and private RCHs. Episodes of ICP observations among AHCPs and doctors were also seldom observed in this setting. Thus, nurses, doctors, and AHCPs were grouped as professional staff categories for further analysis (Table 2).

\section{Hand hygiene performance}

Healthcare workers should perform hand hygiene during the "five moments for hand hygiene." In this study, the observation numbers of five moments showed $30.9 \%$ before touching a resident; $1.4 \%$ before a clean or aseptic procedure (e.g., before nasogastric tube feeding or changing dressing); $1.4 \%$ after blood, body fluid, secretion, excreta, wound, or mucous membrane exposure risk (e.g., after changing diaper); $50.2 \%$ after touching a resident; and $16.2 \%$ after touching contaminated items or the residents' surrounding environment.

The HWs had poor hand hygiene performance before patient contact (98\% failed to perform) and after coming into contact with the patients' surrounding (97\% failed to perform). In comparison, they showed better hand hygiene after body fluid exposure risk (only 54\% failed to perform).

The hand hygiene performance of the professional staff and HWs is better than that of PCWs (Table 2). The best and worst hand hygiene practices were observed among the professional staff and the PCWs, respectively. The professional staff (well-performed: $5.8 \%$, performed: $30.3 \%$ ) and HWs (well-performed: $2.6 \%$, performed: $16.6 \%$ ) in subsidized $\mathrm{RCHs}$ performed better 
Table 1 Demographic data of RCHs

\begin{tabular}{llll}
\hline Demographics & $\begin{array}{l}\text { Total } \\
\mathbf{n}(\%)\end{array}$ & $\begin{array}{l}\text { Subsidized RCHs } \\
\mathbf{n}(\%)\end{array}$ & $\begin{array}{l}\text { Private RCHs } \\
\mathbf{n}(\%)\end{array}$ \\
\hline Number of observations & $2284(100)$ & $1231(53.9)$ & $1053(46.1)$ \\
Number of residents & $461(100)$ & $212(45.9)$ & $249(54.1)$ \\
Number of healthcare workers & $140(100)$ & $78(55.7 \%)$ & $62(55.7)$ \\
- Nurses: & $31(22.1)$ & $15(19.2)$ & $16(25.8)$ \\
- Health workers: & $17(12.1)$ & $9(11.5)$ & $8(12.9)$ \\
- Personal Care workers: & $92(65.7)$ & $54(69.2)$ & $38(61.2)$ \\
Number of sinks for hand washing & $157(100)$ & $82(52.2)$ & $75(47.8)$ \\
Number of alcohol hand rubs & $50(100)$ & $15(30)$ & $35(70)$
\end{tabular}

${ }^{a}$ include registered nurses and enrolled nurses

than the professional staff (well-performed: 5.9\%, performed: 12.1\%) and HWs (well performed: 0\%, performed: 6.7\%) in private homes (Table 2). Post-hoc analysis using the Bonferroni multiple comparison also indicated that the hand hygiene of professional staff was significantly different from those of HWs and PCWs $(\mathrm{F}=27.54, p<0.001)$ (Table 3), wherein the professional staff performed better than HWs and PCWs.

Overall hand hygiene performance among healthcare workers was inadequate in RCHs. The missing rate in private RCHs (87\%) was slightly higher than that in subsidized RCHs (83\%) (Table 4). The use of soap and water to wash hands (82\%) was obviously higher than using ABHR (18\%) among healthcare workers. However, the use of ABHR was more frequent among the professional staff $(8 \%)$ than HWs (4\%) and PCWs (1\%) (Table 5). Ttest results showed there was no significant difference in hand hygiene performance between private and subsidized RCHs ( $\mathrm{t}=1.65, p=0.1)$ and between common areas and bedroom areas $(\mathrm{t}=0.74, p=0.92)$ (Table 4).

\section{Use of gloves}

There was a low number of observations before aseptic task (1.4\%) and after body fluid exposure risk (1.4\%) moments. About $67 \%$ were presented as not applicable among the use of gloves observations. However, the observations showed that $77.9 \%$ improperly performed this practice (Table 3). For example, most of the healthcare workers did not even change gloves between patient contacts.

The observations for the proper use of gloves were $54.7 \%$ in professional staff (mainly nurses), $17.8 \%$ in HWs, and $16.8 \%$ in PCWs. A significant difference was found in the performance score of using gloves via the

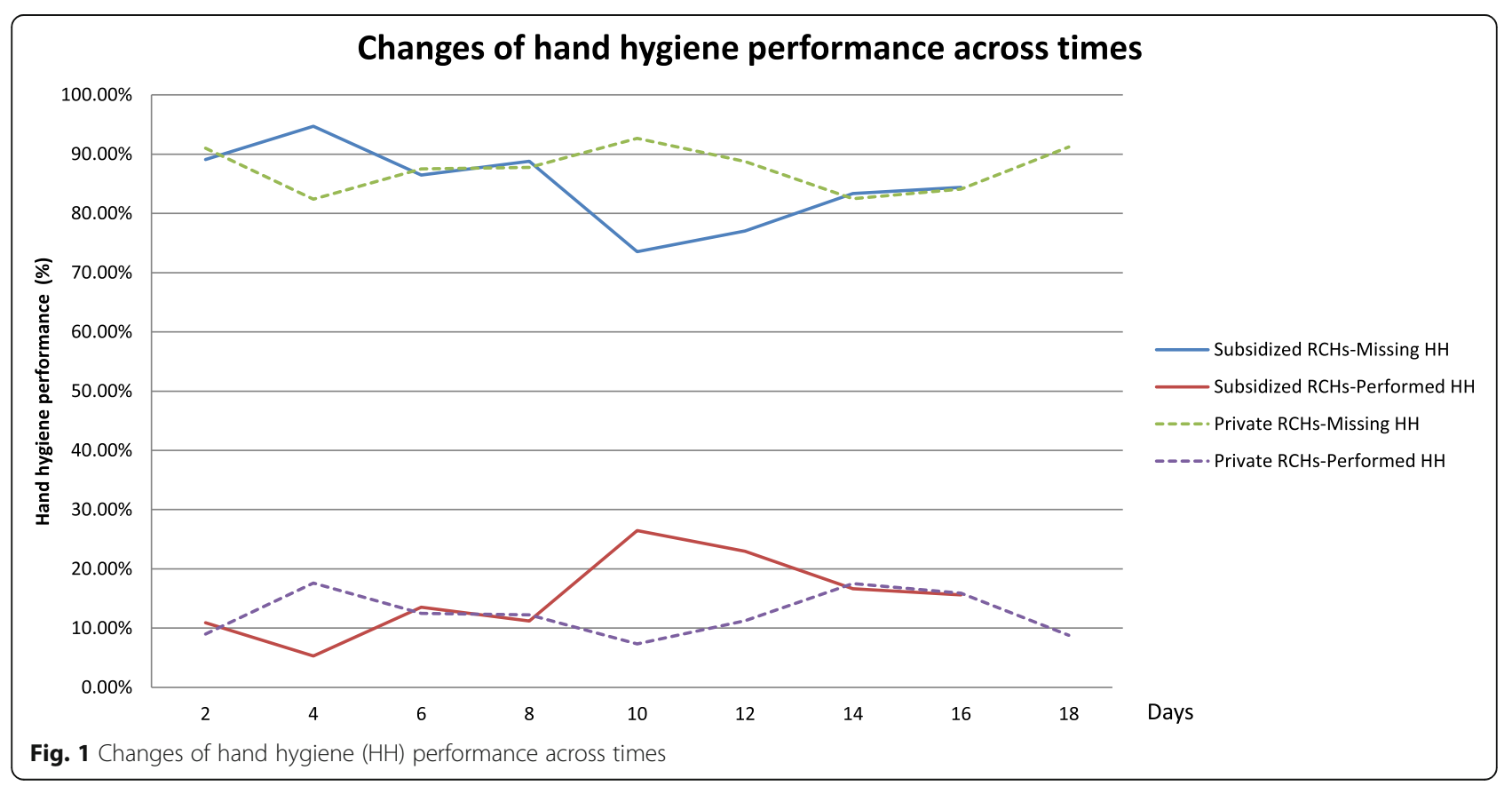


Table 2 Comparison between subsidized and private RCHs regarding hand hygiene, use of gloves and respiratory protection performance of different healthcare workers

\begin{tabular}{|c|c|c|c|c|c|c|}
\hline & \multicolumn{3}{|c|}{ Subsidized RCH } & \multicolumn{3}{|c|}{ Private $\mathrm{RCH}$} \\
\hline & $\begin{array}{l}\text { PCWs, } \\
\text { n (\%) }\end{array}$ & $\begin{array}{l}\text { HWs, } \\
\text { n (\%) }\end{array}$ & Professional staffa ${ }^{\mathrm{a}}$ n (\%) & $\begin{array}{l}\text { PCWs, } \\
\text { n (\%) }\end{array}$ & $\begin{array}{l}\text { HWs, } \\
\text { n (\%) }\end{array}$ & Professional staff ${ }^{\mathrm{a}}, \mathrm{n}(\%)$ \\
\hline \multicolumn{7}{|l|}{ Hand Hygiene } \\
\hline Missing & $742(87.6)$ & $185(80.8)$ & $99(63.9)$ & $553(88.2)$ & $112(93.3)$ & $251(82)$ \\
\hline Performed & 98 (11.6) & $38(16.6)$ & $47(30.3)$ & $66(10.5)$ & $8(6.7)$ & $37(12.1)$ \\
\hline Well performed & $7(0.8)$ & $6(2.6)$ & $9(5.8)$ & $8(1.3)$ & $0(0.0)$ & $18(5.9)$ \\
\hline \multicolumn{7}{|l|}{ Use of gloves } \\
\hline Not applicable & $584(68.9)$ & $206(90)$ & $134(86.5)$ & $330(52.6)$ & $53(44.2)$ & $263(85.9)$ \\
\hline Missing & $3(0.4)$ & $3(1.3)$ & $1(0.6)$ & $5(0.8)$ & $0(0.0)$ & $1(0.3)$ \\
\hline Improperly performed & $219(25.9)$ & $11(4.8)$ & $5(3.2)$ & $239(38.1)$ & $60(50)$ & $22(7.2)$ \\
\hline Properly performed & $41(4.8)$ & $9(3.9)$ & $15(9.7)$ & $53(8.5)$ & $7(5.8)$ & $20(6.5)$ \\
\hline \multicolumn{7}{|l|}{ Respiratory protection } \\
\hline Missing & $214(25.3)$ & $71(31.0)$ & $51(32.9)$ & $273(43.5)$ & $3(2.5)$ & $114(37.3)$ \\
\hline Improperly performed & $8(0.9)$ & $3(1.3)$ & $2(1.3)$ & $1(0.2)$ & $0(0.0)$ & $0(0.0)$ \\
\hline Properly performed & $625(73.8)$ & $155(67.7)$ & $102(65.8)$ & $353(56.3)$ & $117(97.5)$ & $192(62.7)$ \\
\hline
\end{tabular}

$n=$ total numbers of observed infection control practice episodes

$\%=$ percentage of compliance in each of the total number of observed infection control practice episodes

${ }^{\text {a }}$ Professional staff include nurses, doctors, and allied health professionals

ANOVA test $(\mathrm{F}=40.13, p<0.001)$ (Table 3). Post-hoc analyses showed that the professional staff performed significantly better than PCWs $(p<0.001)$ and HWs $(p<$ 0.01) (Table 3).

On the one hand, there was a slightly higher frequency of improper use of gloves in private $(79 \%)$ than in subsidized (77\%) RCHs (Table 4). On the other hand, there were 6 and 5\% who failed to use gloves in subsidized and private $\mathrm{RCHs}$, respectively. A significant difference in the proper use of gloves between subsidized and private $\mathrm{RCHs}(\mathrm{t}=-6.81, p<0.001)$ and between common areas and bedroom areas $(\mathrm{t}=-3.84, p<0.001)$ was found (Table 4).

\section{Respiratory protection}

Around $31.8 \%$ failed to wear the mask as needed (Table 4). However, most of them knew how to wear the required mask properly. Moreover, HWs performed better respiratory protection (77\% performed properly) than the professional staff (65\%) and PCWs (66\%). A

Table 3 Compliance with infection control guidelines among healthcare workers (HCWs)

\begin{tabular}{|c|c|c|c|c|}
\hline & Professional staff ${ }^{a}, \mathrm{n}(\%)$ & $\begin{array}{l}\text { HWs, } \\
\text { n (\%) }\end{array}$ & $\begin{array}{l}\text { PCWs, } \\
\text { n (\%) }\end{array}$ & $\begin{array}{l}\text { ANOVA test, } \\
p \text {-value }\end{array}$ \\
\hline Hand hygiene & & & & $F=27.54, p<0.001$ \\
\hline Missing & $350(75.92)$ & $297(85.1)$ & $1295(87.86)$ & \\
\hline Performed & $84(18.22)$ & $46(13.18)$ & $164(11.13)$ & \\
\hline Well performed & $27(5.86)$ & $6(1.72)$ & $15(1.02)$ & \\
\hline Use of gloves & & & & $\mathrm{F}=40.13, p<0.001$ \\
\hline Missing & $2(3.13)$ & $3(3.33)$ & $8(1.43)$ & \\
\hline Improperly performed & $27(42.19)$ & $71(78.89)$ & $458(81.79)$ & \\
\hline Properly performed & $35(54.69)$ & $16(17.78)$ & $94(16.79)$ & \\
\hline Respiratory protection & & & & $\mathrm{F}=11.08, p<0.001$ \\
\hline Missing & $165(35.79)$ & $74(21.2)$ & $487(33.04)$ & \\
\hline Improperly performed & $2(0.43)$ & $3(0.86)$ & $9(0.61)$ & \\
\hline Properly performed & $294(63.77)$ & 272 (77.94) & $978(66.35)$ & \\
\hline
\end{tabular}

$n=$ total numbers of observed infection control practice episodes

$\%=$ percentage of compliance in each of the total number of observed infection control practice episodes

${ }^{\text {a }}$ Professional staff include nurses, doctors, and allied health professionals 
Table 4 Compliance with infection control guidelines in type of RCHs (subsidized and private RCHs) and location (common area and bedroom area)

\begin{tabular}{|c|c|c|c|c|c|c|c|}
\hline & $\begin{array}{l}\text { Overall, } \\
\mathrm{n}(\%)\end{array}$ & $\begin{array}{l}\text { Subsidized RCHs, } \\
\text { n(\%) }\end{array}$ & $\begin{array}{l}\text { Private RCHs, } \\
\mathrm{n}(\%)\end{array}$ & t-test, $p$ value & $\begin{array}{l}\text { Common areas, } \\
n(\%)\end{array}$ & $\begin{array}{l}\text { Bedroom areas, } \\
\mathrm{n}(\%)\end{array}$ & t-test, $p$ value \\
\hline Hand hygiene & & & & $\begin{array}{l}t=1.65, p= \\
0.10\end{array}$ & & & $\begin{array}{l}t=0.74, p= \\
0.92\end{array}$ \\
\hline Missing & $\begin{array}{l}1942 \\
(85.03)\end{array}$ & $1026(83.35)$ & 916 (86.99) & & $881(84.87)$ & 1061 (85.5) & \\
\hline Performed & $294(12.87)$ & $183(4.87)$ & $111(10.54)$ & & $136(13.1)$ & $158(12.68)$ & \\
\hline Well performed & $48(2.10)$ & $22(1.79)$ & $26(2.47)$ & & $21(2.02)$ & $27(2.70)$ & \\
\hline Use of gloves & & & & $\begin{array}{l}\mathrm{t}=-6.81, p< \\
0.001\end{array}$ & & & $\begin{array}{l}\mathrm{t}=-3.84, p< \\
0.001\end{array}$ \\
\hline Missing & $13(1.82)$ & $6(1.95)$ & $5(1.23)$ & & $3(1.05)$ & $10(2.34)$ & \\
\hline $\begin{array}{l}\text { Improperly } \\
\text { performed }\end{array}$ & $556(77.87)$ & $235(76.55)$ & $321(78.87)$ & & $240(83.62)$ & $316(74.00)$ & \\
\hline $\begin{array}{l}\text { Properly } \\
\text { performed }\end{array}$ & $145(20.31)$ & $66(21.5)$ & 81 (19.9) & & $44(15.33)$ & $101(23.65)$ & \\
\hline $\begin{array}{l}\text { Respiratory } \\
\text { protection }\end{array}$ & & & & $\begin{array}{l}\mathrm{t}=4.74 \\
p<0.001\end{array}$ & & & $\begin{array}{l}\mathrm{t}=-1.841 .84 \\
p=0.06\end{array}$ \\
\hline Missing & 726 (31.79) & $338(27.46)$ & 390 (37.04) & & 351 (33.82) & $375(30.1)$ & \\
\hline $\begin{array}{l}\text { Improperly } \\
\text { performed }\end{array}$ & $14(0.61)$ & $13(1.06)$ & $1(0.09)$ & & $5(0.48)$ & $9(0.72)$ & \\
\hline $\begin{array}{l}\text { Properly } \\
\text { performed }\end{array}$ & $1544(67.6)$ & $880(71.49)$ & $662(62.87)$ & & $682(65.7)$ & $862(69.8)$ & \\
\hline
\end{tabular}

$n=$ total numbers of observed infection control practice episodes

$\%=$ percentage of compliance in each of the total number of observed infection control practice episodes

significant difference in respiratory protection among occupations was found ( $\mathrm{F}=11.08, p<0.001)$ (Table 3$)$.

The practice of respiratory protection was better in subsidized (72\%) than in private $\mathrm{RCHs}(63 \%)$. A significant difference was found in the practice of respiratory protection between subsidized and private RCHs $(\mathrm{t}=4.74, p<0.001)$. However, there was no significant difference of such a practice between common areas and bedroom areas $(\mathrm{t}=-1.84, p=$ 0.06) (Table 4).

\section{Association between hand hygiene performance and use of gloves}

There was a negative correlation between the proper use of gloves and hand hygiene performance $(\mathrm{r}=-0.239$, $p<0.001)$.

\section{Discussion}

To the best of our knowledge, this is the first study conducted using a unit-based observation approach, which separated the RCHs into different units according to the nature and intensity of care provision. Although there was no significant differences found among the different units, such information provided justification to inform future research. Furthermore, this study reported the changes of hand hygiene compliance over a period of 23 weeks. Surprisingly, there were no significant changes observed, thereby contradicting previous studies [23]. However, it was plausible that the hand hygiene performance was too low to explain the change. Floor effect was considered in this case.

Many researchers stated that hand hygiene is the most effective element in preventing infections. A systemic review of the impact of hand hygiene on risk infections in

Table 5 Use of handrub and handwashing among healthcare workers

\begin{tabular}{llll}
\hline & \multicolumn{2}{l}{ Occupations } & \\
\cline { 2 - 4 } & $\begin{array}{l}\text { PCWs, } \\
\mathbf{n}(\%)\end{array}$ & $\mathbf{H W s ,}$ & Professional staff, $\mathbf{n}(\%)$ \\
\hline Alcohol-based handrub & $11(1)$ & $14(4)$ & $38(8)$ \\
Handwashing using soap and water & $168(11)$ & $38(11)$ & $73(16)$ \\
Hand hygiene missing & $1295(88)$ & $297(85)$ & $350(76)$ \\
\hline
\end{tabular}


nursing homes revealed that the infection rate decreased when at least one hand hygiene-related intervention (e.g., availability of ABHR) was applied in the study [24]. However, the overall hand hygiene performance was still poor $(15 \%)$ in the current study even though there was sufficient provision of ABHR. This result is similar with that of Smith et al. [25] and Ho et al. [26], who reported that the hand hygiene performance rate is $14.7 \%$ in two long-term care facilities and ranged from $19.5-27 \%$ in subsidized RCHs. Moreover, the availability of ABHR in common areas was better than in the bedroom areas among subsidized and private $\mathrm{RCHs}$. Yet, there was no difference found in the hand hygiene performance between common areas and bedroom areas. This indicated that healthcare workers had no intention to perform hand hygiene even with the presence of ABHR, at least in this study. This contradicts past studies, which reported an increase in hand hygiene compliance with increased availability of ABHR [27, 28]. In fact, some studies showed that increase hand hygiene compliance not only increased ABHR but also staff education on the use of such material [25]. PCWs seldom used ABHR compared with other healthcare workers in the current study. Indeed, it was predicted that professionals would have higher hand hygiene compliance than PCWs and HWs due to differences in educational background. Studies on hand hygiene behavior always focused on professional staff in hospital settings. However, this may not reflect the same situation in the $\mathrm{RCH}$ setting in the current study, as many healthcare workers completed lower educational levels in $\mathrm{RCHs}$ (most staff were PCWs and HWs with secondary school education). Therefore, further assessment of hand hygiene behaviors among PCWs and HWs in the RCH setting is necessary.

In the present study, hand hygiene performance was the best after body fluid exposure risk ( $46 \%$ performed), after the aseptic procedure (25\% performed), and after patient contact ( $25 \%$ performed) compared with before patient contact $(2 \%)$ and after contact with the patients' surroundings $(3 \%)$. This result is consistent with previous research, which indicated a significantly higher hand hygiene performance after body fluid exposure, aseptic procedure, and after patient contact compared to before patient contact and after patient surrounding contact [29]. Furthermore, another study showed that the assistant healthcare workers had the worst hand hygiene compliance in each moment compared with nurses and doctors in Turkey [30]. The current study revealed a similar result in which PCWs (with similar job duties to assistant healthcare workers) had the worst performance in each moment compared with the professional staff. It is likely that healthcare workers think that the residents' surroundings colonize with less microorganisms and lower risk of infection [29]. Moreover, in this study, the best performance in the use of gloves was the moment before coming into contact with the patients (38\%) and before performing the aseptic technique (68\%). It seemed that healthcare workers tend to protect themselves rather than protect others [31]. Therefore, evidence from studies should be shared to convince healthcare workers to practice hand hygiene effectively at each moment.

Meanwhile, wearing gloves diminished the transmission of organisms via the healthcare workers' hand and protected them, whereas the improper use of gloves increased the risk of organism transmission [32]. The use of gloves, however, is not a substitute for hand hygiene. In fact, many studies have shown that hand hygiene is worse in case of using gloves. The current study also found that hand hygiene performance decreased with the increased use of gloves. PCWs had the most frequent contact with residents. Yet, they had the worst performance in hand hygiene and frequently improper use of gloves among the healthcare workers observed in the study. For example, they did not wash their hands after removing the gloves (missing $=98 \%$ ) and did not change gloves between care procedures among residents (missing $=66.4 \%$ ). Furthermore, they tended to perform hand hygiene only after completing specific successive tasks for all residents.

Respiratory tract infection (1.3\%) is the most common type of infection in RCHs [7]. Respiratory protection is an effective preventive measure to prevent droplet transmission. In this study, most healthcare workers can correctly wear the surgical mask in case respiratory protection was required, yet $30 \%$ of healthcare workers failed to wear a surgical mask while performing patient care procedures. There was no observational study on wearing surgical mask in RCHs. The result is the same as that reported in a past study, which indicated that most healthcare workers wore a surgical mask correctly in the hospital setting [33].

Overall, the hand hygiene and respiratory protection performance scores showed no significant difference between common areas and bedroom areas in private and subsidized RCHs. However, the use of gloves had higher frequency in the bedroom areas than in common areas in the moments before performing an aseptic technique (i.e., wound dressing) and before coming into contact with bodily fluids (i.e., changing diaper). Respiratory protection, the use of gloves, and hand hygiene had just slightly better performance scores in subsidized than private $\mathrm{RCHs}$. There was not enough significant difference observed in this study, although the manpower practice was much satisfactory in subsidized RCHs than in private ones. Some authors mentioned that ICP was performed better in subsidized RCHs with abundant 
resources [34]. However, the sample is not adequate to conduct a comparison with the current study.

Thus far, studies on ICP in Hong Kong RCHs by observational design without applying interventions have been limited. Wong et al. reported the first survey on the trends of ICP from 2005 to 2014, revealing that the overall trend of ICP was improved and that ICP in subsidized $\mathrm{RCHs}$ is better than in private $\mathrm{RCHs}$ due to the related factors (i.e., educational level of staff, resident-tostaff manpower ratio, and compliance with minimum statutory standards in private RCHs) [35]. However, Wong and colleagues only observed two healthcare workers (the infection control officer and one care worker) in each visit per year. Therefore, their results might not reflect the ICP among the majority of healthcare workers. In the current study, although comparisons between subsidized and private RCHs was limited, as the sampling size was not adequate, the results can still reflect the preliminary natural performance of ICP among healthcare workers, because continuous observations for 2-3 weeks were made, and the observations were carried out randomly during healthcare workers' routine caring procedure in random instances.

The most observed ICP elements in this study were hand hygiene, use of gloves, and respiratory protection. However, other elements were not shown in this research, such as disinfecting used surfaces/equipment, handling of linen, handling of clinical waste, handling of sharp equipment, use of PPEs, and the likelihood of hand colonization. These elements were omitted from the observations, because these were not routinely performed and can only be observed by chance. In the future, we can obtain data from such practices by using a questionnaire if the procedure will be seldom observed. The generalizability of the study can also be improved by recruiting more participants in the sample of $\mathrm{RCHs}$ in future studies.

Meanwhile, healthcare workers had adequate levels of skills and knowledge on ICP [35]. However, ICP among healthcare workers was still poor in the current study. This implies that the adoption of ICP is always difficult to implement even if the staff are equipped with adequate knowledge. Compliance with ICP depends on a comprehensive theory behind [36]. PCWs are the main caregivers for residents in $\mathrm{RCHs}$ setting. Their workloads are much heavier than those of other types of healthcare workers in RCHs. Thus, future studies can give more focus on their ICP behaviors in this setting.

However, the findings of this study may not fully reflect the ICP practice during the COVID-19 epidemic. Based on the experiences learned when Hong Kong dealt with the severe acute respiratory syndrome (SARS) epidemic in 2003, many people reacted swiftly during the COVID-19 epidemic by wearing surgical masks in public areas and by following strict hand hygiene practices [37]. The residential care setting has been shown to be effective during the COVID-19 epidemic, in that no COVID19 confirmed cases have been reported in $\mathrm{RCHs}$ or longterm care facilities at least in the first 6 months since the coronavirus first emerged in Wuhan in January [38]. $\mathrm{RCHs}$ are required by the Government of Hong Kong Special Administrative Region to promote infection control policies, including but not limited to, providing training on hand hygiene and the use of PPEs [39], thus resulting in higher ICP compliance in RCHs.

There are some limitations in the study that must be mentioned. First, whether the procedures were not part of the daily routine in some ICP episodes cannot be easily observed. Thus, the study failed to demonstrate the comprehensive ICP in RCHs. Second, the private RCHs refused to allow the researcher to observe the bedbound elderly (18 residents) housed on the same floor. Hence, the results may not totally reflect the actual ICP compliance in private RCHs.

\section{Conclusions}

Thus far, only a few studies on ICP in RCHs in Hong Kong have been conducted using the observational method over a period of time. To help address this gap, this study presents the preliminary phenomenon of ICP among healthcare workers in this setting. Overall ICP on hand hygiene, use of gloves, and respiratory hygiene was poor, thereby increasing the risk of HAI among healthcare workers and residents. In light of such findings, there should be continued monitoring and training among healthcare workers, particularly PCWs, who have the most frequent contact with residents in these healthcare service settings. Furthermore, appropriate infection prevention and control guidelines for this specific setting should be designed and implemented.

\section{Abbreviations}

RCHs: Residential Care Homes; ICP: Infection control practice; HAl: Healthcare associated infection; HW: Health worker; PCW: Personal care worker.; AHCP: Allied health care professionals; ABHR: Alcohol-based hand rub

\section{Acknowledgements}

We wish to thank the subsidized and private residential care homes for joining this study. We also thank Mr. Tor Michael Rossing, SAG Flowmedik Oy, Helsinki, Finland, for his provision of the eRub platform in the data collection and encrypted data storage. Likewise, we wish to thank Professor Doris Yu, Dr. Eileen Cheng, Dr. Doris Leung, and Dr. Angela Leung for their valuable comments while we were drafting the proposal.

\section{Authors' contributions}

Conception and design of the study: SCL and JKLA. Acquisition of data: JKLA Data analysis: SCL and JKLA. Interpretation of data: SCL and JKLA. Drafting the manuscript: SCL and JKLA. Critically review: SCL and LKPS. All authors reviewed and approved the manuscript.

\section{Funding}

This project was partially supported by Start-up Fund, School of Nursing, The Hong Kong Polytechnic University (Reference No.: P0000247;1-BE1S). The 
funding body had no influence on the design, collection, analysis and interpretation of data or in the manuscript writing.

\section{Availability of data and materials}

The data and materials are available from the corresponding authors on reasonable request.

\section{Ethics approval and consent to participate}

This study was approved by the Human Subjects Ethics Sub-Committee of the Hong Kong Polytechnic University (Reference No.: HSEARS20190618003). All the participants provided their written informed consent prior to participation. The participants were assured of their anonymity and confidentiality, and their rights of withdrawal were respected.

\section{Consent for publication}

Not Applicable.

\section{Competing interests}

The authors report no conflict of interest relevant to this study.

\section{Author details}

${ }^{1}$ School of Nursing, The Hong Kong Polytechnic University, Hong Kong, Hong Kong SAR. ${ }^{2}$ School of Nursing, Tung Wah College, Hong Kong, Hong Kong SAR. ${ }^{3}$ Squina International Centre for Infection Control, The Hong Kong Polytechnic University, Hong Kong, Hong Kong SAR.

Received: 25 June 2020 Accepted: 5 January 2021

Published online: 14 January 2021

\section{References}

1. Pereira FMV, Lam SC, Chan JHM, Malaguti-Toffano SE, Gir E. Difference in compliance with standard precautions by nursing staff in Brazil versus Hong Kong. Am J Infect Control. 2015;43(7):769-72.

2. Bates DW, Larizgoitia I, Prasopa-Plaizier N, Jha AK. Global priorities for patient safety research. BMJ. 2009;338:b1775.

3. Zingg W, Holmes A, Dettenkofer M, Goetting T, Secci F, Clack L, Allegranzi B, Magiorakos AP, Pittet D. Hospital organisation, management, and structure for prevention of health-care-associated infection: a systematic review and expert consensus. Lancet Infect Dis. 2015;15(2):212-24.

4. Herzig CT, Dick AW, Sorbero M, Pogorzelska-Maziarz M, Cohen CC, Larson EL, Stone PW. Infection trends in US nursing homes, 2006-2013. J Am Med Dir Assoc. 2017;18(7):635-e9.

5. Eikelenboom-Boskamp A, Cox-Claessens JH, Boom-Poels PG, Drabbe MI, Koopmans RT, Voss A. Three-year prevalence of healthcare-associated infections in Dutch nursing homes. J Hosp Infect. 2011;78(1):59-62.

6. Suetens C. Healthcare-associated infections in European long-term care facilities: how big is the challenge? Eurosurveillance. 2012;17(35):20259.

7. Choy C, Chen H, Yau C, Hsu E, Chik NY, Wong AT. Prevalence of infections among residents of residential care homes for the elderly in Hong Kong. Hong King Med J. 2016;22(4):347-55.

8. Chen H, Au KM, Hsu KE, Lai CK, Myint J, Mak YF, Lee SY, Wong TY, Tsang NC. Multidrug-resistant organism carriage among residents from residential care homes for the elderly in Hong Kong: a prevalence survey with stratified cluster sampling. Hong Kong Med J. 2018;24(4):350-60.

9. Ho PL, Wang TK, Ching P, Mak GC, Lai E, Yam WC, Seto WH. Epidemiology and genetic diversity of methicillin-resistant Staphylococcus aureus strains in residential care homes for elderly persons in Hong Kong. Infect Control Hosp Epidemiol. 2007;28(6):671-8.

10. Cheng VC, Tai JW, Wong ZS, Chen JH, Pan KB, Hai Y, Ng WC, Chow DM, Yau MC, Chan JF, Wong SC. Transmission of methicillin-resistant Staphylococcus aureus in the long term care facilities in Hong Kong. BMC Infect Dis. 2013; 13(1):205

11. Srinivasan A, Craig M, Cardo D. The power of policy change, federal collaboration, and state coordination in healthcare-associated infection prevention. Clin Infect Dis. 2012;55(3):426-31.

12. Gammon J, Morgan-Samuel H, Gould D. A review of the evidence for suboptimal compliance of healthcare practitioners to standard/universal infection control precautions. J Clin Nurs. 2008;17(2):157-67.

13. Lam SC. Validation and cross-cultural pilot testing of compliance with standard precautions scale: self-administered instrument for clinical nurses. Infect Control Hosp Epidemiol. 2014;35(5):547-55.
14. Social Welfare Department, Hong Kong SAR Government. Code of practice for residential care homes (elderly persons). Available from: http://www.swd. gov.hk/doc/LORCHs/CodeofPractice_E_201303_20150313R3.pdf. Accessed 8 Jan 2019.

15. Schweon SJ, Edmonds SL, Kirk J, Rowland DY, Acosta C. Effectiveness of a comprehensive hand hygiene program for reduction of infection rates in a long-term care facility. Am J Infect Control. 2013;41(1):39-44.

16. High KP, Juthani-Mehta M, Quagliarello VJ. Infectious diseases in the nursing home setting: challenges and opportunities for clinical investigation. Clin Infect Dis. 2010;51(8):931-6.

17. Murad K, Kitzman DW. Frailty and multiple comorbidities in the elderly patient with heart failure: implications for management. Heart Fail Rev. 2012;17(4-5):581-8.

18. Migdal A, Yarandi SS, Smiley D, Umpierrez GE. Update on diabetes in the elderly and in nursing home residents. J Am Med Dir Assoc. 2011;12(9):62732.

19. Løyland B, Wilmont S, Cohen B, Larson E. Hand-hygiene practices and observed barriers in pediatric long-term care facilities in the New York metropolitan area. Int J Qual Health Care. 2016;28(1):74-80.

20. Lodico MG, Spaulding DT, Voegtle KH. Methods in educational research: from theory to practice. San Francisco: Wiley; 2010.

21. World Health Organization. WHO guidelines on hand hygiene in health care. Available from:http://apps.who.int/iris/bitstream/handle/10665/44102/ 9789241597906_eng.pdf?sequence=1. Accessed 8 Jan 2019.

22. Gwet KL. Handbook of inter-rater reliability: the definitive guide to measuring the extent of agreement among raters. Gaithersburg: Advanced Analytics, LLC; 2014

23. Lam SC, Tse FWF, Suen LKP. Quantifying the duration of Hawthorne effect in observing hand hygiene compliance: changes in compliance rate in 11 weeks. In: the 23rd east Asian forum of nursing scholars (EAFONS) 2020 (A00379; p. 80). Chiang Mai: Faculty of Nursing, Chiang Mai University; 2020.

24. Hocine MN, Temime L. Impact of hand hygiene on the infectious risk in nursing home residents: a systematic review. Am J Infect Control. 2015; 43(9):e47-52.

25. Smith A, Carusone SC, Loeb M. Hand hygiene practices of health care workers in long-term care facilities. Am J Infect Control. 2008;36(7):492-4.

26. Ho ML, Seto WH, Wong LC, Wong TY. Effectiveness of multifaceted hand hygiene interventions in long-term care facilities in Hong Kong: a clusterrandomized controlled trial. Infect Control Hosp Epidemiol. 2012;33(8):76.

27. Chen YC, Sheng WH, Wang JT, Chang SC, Lin HC, Tien KL, Hsu LY, Tsai KS. Effectiveness and limitations of hand hygiene promotion on decreasing healthcare-associated infections. PLoS One. 2011;6(11):e27163.

28. Santana SL, Furtado GH, Coutinho AP, Medeiros EA. Assessment of healthcare professionals' adherence to hand hygiene after alcohol-based hand rub introduction at an intensive care unit in Sao Paulo, Brazil. Infect Control Hosp Epidemiol. 2007;28(3):365-7.

29. Anwar MM, Elareed HR. Improvement of hand hygiene compliance among health care workers in intensive care units. J Prev Med Hygiene. 2019;60(1): E31.

30. Teker B, Ogutlu A, Gozdas HT, Ruayercan S, Hacialioglu G, Karabay O. Factors affecting hand hygiene adherence at a private hospital in Turkey. Eur J Med. 2015;47(3):208.

31. Lam SC, So FWK, Cheng HL, Yu DSF, Suen LKP, Leung DYP, Leung AYM. Reasons for performing suboptimal infection control practice among healthcare staff in residential care homes: preliminary findings of a qualitative study. In: the 23rd East Asian Forum of Nursing Scholars (EAFONS) 2020 (A00920; p. 75). Chiang Mai, Thailand: Faculty of Nursing, Chiang Mai University; 2020.

32. Girou E, Chai SH, Oppein F, Legrand P, Ducellier D, Cizeau F, Brun-Buisson C Misuse of gloves: the foundation for poor compliance with hand hygiene and potential for microbial transmission? J Hosp Infect. 2004;57(2):162-9.

33. Chau JP, Thompson DR, Lee DT, Twinn S. Infection control practices among hospital health and support workers in Hong Kong. J Hosp Infect. 2010; 75(4):299-303.

34. Bostick JE, Rantz MJ, Flesner MK, Riggs CJ. Systematic review of studies of staffing and quality in nursing homes. J Am Med Dir Assoc. 2006;7(6):36676.

35. Wong GC, Ng T, Li T. Infection control in residential care homes for the elderly in Hong Kong. Hong Kong Med J. 2019;25(2):113-9.

36. Michinov E, Buffet-Bataillon S, Chudy C, Constant A, Merle V, Astagneau P. Sociocognitive determinants of self-reported compliance with standard 
precautions: development and preliminary testing of a questionnaire with French health care workers. Am J Infect Control. 2016;44(1):14-9.

37. Lum T, Shi C, Wong G, Wong K. COVID-19 and long-term care policy for older people in Hong Kong. J Aging Soc Policy. 2020;32(4-5):373-9. https:// doi.org/10.1080/08959420.2020.1773192.

38. The Government of Hong Kong Special Adminstrative Region. CE inspects virus tests for staff of residential care home for the elderly. 2020.Press release on 14 July https://www.info.gov.hk/gia/general/202007/14/P202 0071400961.htm

39. Woo J. COVID-19 and residential care homes in Hong Kong. J Nurs Home Res. 2020;6:20-1. Published online July 6, 2020. https://doi.org/10.14283/ jnhrs.2020.4

\section{Publisher's Note}

Springer Nature remains neutral with regard to jurisdictional claims in published maps and institutional affiliations.

Ready to submit your research? Choose BMC and benefit from:

- fast, convenient online submission

- thorough peer review by experienced researchers in your field

- rapid publication on acceptance

- support for research data, including large and complex data types

- gold Open Access which fosters wider collaboration and increased citations

- maximum visibility for your research: over $100 \mathrm{M}$ website views per year

At $\mathrm{BMC}$, research is always in progress.

Learn more biomedcentral.com/submissions 